\title{
Changes in Open Innovation Tactics after Lehman Shock Analysis of Toray Group's Patent Application
}

\author{
Tomohiro MAEKAWA \\ Suntory Global Innovation Center Limited, 1-1 Seikadai 8-chome,Seikacho, Sorakugun ,Kyoto, 619-0284 Japan
}

\begin{abstract}
This was the first study to analyze changes in Open Innovation (hereinafter "OI") tactics caused by deteriorating business environment objectively and quantitatively for one enterprise or group of enterprises. In this study, changes in OI tactics caused by deteriorating business environment were revealed with quantitatively analyzing patent applications of Toray group. Firstly, $R \& D$ areas was analyzed. In the analysis, the ratio of inventors other than Toray was used. Secondly, R\&D focusing activities was analyzed. In the analysis, the ratio of patent applications / $R \& D$ investment amount was calculated. The analysis result revealed that production of core technology output was strengthening in Toray's OI tactics after Lehman shock.
\end{abstract}

Key words: Open innovation, Toray, Lehman shock

\section{Introduction}

What kind of change will appear in OI policy of enterprise when facing major changes in the business environment? OI is a concept that Chesbrough[1] presented in 2003 in his book, he defined OI as "to create value by organically combining internal and external ideas". Regarding necessity of OI, Motohashi et al. [2] explains that OI is necessary because it is difficult for $\mathrm{R} \& \mathrm{D}$ resources to balance the speed of research development with the scope expansion. On the other hands, there are previous studies to explain awareness reform of enterprise stuff as for OI. Hoshino [3] explains that Toray and Ajinomoto utilize OI or their own conscious reform to resolve the NIH syndrome.

However it is under study how OI tactics changes when an enterprise faces a major deterioration of business environment like the Lehman shock. This is because OI is relatively new concept and accumulation of practical work in enterprises is small. For the same reason, there are few Japanese enterprises to be studied. Japanese enterprises that advanced OI from a relatively early age are Toray [4] which started in 2002, Osaka gas [5] which started in 2008 and Ajinomoto [6] which started in August 2012. In order for more Japanese enterprises to be able to use OI, it is indispensable to understand the changes in OI tactics caused by deteriorating business environment.

Among Japanese enterprises, Toray group (hereinafter referred to as "Toray") is interesting as a research subject. As Toray promotes OI before the Lehman shock, it is the only enterprise in Japan that can be studied about change in OI tactics caused by deteriorating business environment. Given this situation, changes in OI tactics of Toray should be studied from all angles. In this study, patent applications of Toray are spotted. Attribute information of patent applications can be used as a surrogate variable for $\mathrm{R} \& \mathrm{D}$ output. Therefore the attribute information is also suitable as a surrogate variable to measure changes in OI tactics. In this study, among the change in OI tactics of Toray caused by deteriorating business environment, their patent applications will be quantitatively analyzed. The shift of OI tactics in Toray has been demonstrated.

\section{Lit.review}

\subsection{Open innovation}

There are various previous studies on OI on enterprises. Shimizu et al. [8] introduces OI in terms of advantage and disadvantage. First advantage is that development speed of new products will be faster. Lead time for new product development will be shortened by collaborating with enterprises with higher expertise. Moreover shortened lead time leads to a higher possibility of winning the earnings profit for competitors. Second advantage is to reduce internal management cost of enterprise. Internal management cost of enterprises is reduced since R\&D and marketing are carried out using external management resources. Third advantage is that inventory of management resources within the enterprise progresses. Open procurement of management resources leads to review of management resources existing in the enterprise. And progress in inventory of management resources leads to restructuring of product technology strategy and

*Corresponding author: Tomohiro_Maekawa@suntory.co.jp 
product development strategy. In particular, it is the most important that development priority be determined. Fourth advantage is competitive pressure on internal development within the enterprise. Comparison between internal and external will drastically reduce lack of manners and tension within enterprise and cause revitalization of organization. OI has disadvantage although OI has advantage. First disadvantage is increased cost of organizing. OI promotion requires costs including a wide range of labor such as retrieval of external resources and coordination among organizations. Second disadvantage is leakage of R\&D information and technical information. OI needs measures to search for external technologies with securing anonymity and to enhance possibility of possessing own products and business. Third disadvantage is to decline long-term R\&D mind and core competence. Therefore management of basic research that can maintain core competence is important.

On the other hands, I. Sam [7] describes paradigm shift of food industry and academic institutions and Shimizu et al.[8] explains that OI speeds up R\&D. However they did not demonstrate changes in OI tactics caused by deteriorating business environment. Therefore, there have not been any studies that demonstrated the changes objectively and quantitatively for one enterprise or group of enterprises.

\subsection{Patent analysis for quantitative analysis of $R \& D$ activities}

Patent data is used as a surrogate variable for $R \& D$ achievements from $\mathrm{R} \& \mathrm{D}$ investment. However, as Scherer [9], Pakes [10], Griliches [11] pointed, since each value of patent applications are different, it is problematic to use quantitative indicators such as the number of patent applications and the number of patent registrations as proxy variables of $R \& D$ achievements as they are. The qualitative elements of each patent application must be incorporated into the analysis. Trajtenberg [12] shows that cited number of patent applications is to be analyzed as a qualitative factor and since then the cited number has been utilized by many researchers. Further, for example, attribute information such as the number of objects such as invalidation trial, opponent petition, information provision, the number of IPC classification, the number of claims, the number of inventors, the number of citations or the number of patent family countries, has been utilized by many researchers. And Lanjouw and Schankerman [13] have advanced these research further. They proposed a method of calculating a single value index from multiple attribute information of a patent application. Specifically, they proposed a "single latent variable model" that enhanced the factor analysis method. Regarding quality of patent applications, they showed that significance of indicators obtained in their model is higher than index obtained from one attribute information.
Lanjouw and Schankerman [13] was further developed by research of Yamada [14]. Yamada calculated a single index from 3076 patent data of 40 major Japanese enterprises in 1995 and confirmed that indicator significantly explains registration renewal of patent.

Nishimura et al. [15] analyze inventors of patent application by enterprises participating in bio-cluster and explain that patent value significantly increases through industry-university collaboration. Nishimura et al. normalize data of individual indicators such as the number of claims, the number of inventors, the number of technical fields, and the number of families in order to unify the units of original data, then they calculate principal component score and treat it as a synthetic index.

\subsection{Open innovation strategy of Toray}

Ozeki[4] explains the process of adopting OI and its strategy of Toray. OI was adopting in R \& D of Toray on the occasion of the 2002 management crisis. Objective of adopting OI was speed up and low cost of R \& D. Slogan at the beginning of OI adoption was resolution of NIH syndrome and in 2004 the slogan was "strengthening collaboration and integration." After that, keyword OI came to be specified not only in R \& D strategy but also in Toray's main policy in 2011.

Toray's OI is characterized by the selection of open / closed areas. Toray's core technologies are organic synthetic chemistry, polymer chemistry, biotechnology, and nanotechnology. Toray has developed advanced technology based on core technology and is developing business globally. R \& D of core technology was advanced in black box state. $\mathrm{R} \& \mathrm{D}$ of peripheral technology of core technology OI applied. Besides OI tactics of Toray was flexible. Even with current peripheral technology, those close to core technology were researched and developed in black box state. OI was applied to future core technologies that were close to peripheral technologies. The nature of $R \& D$ theme adopting OI is applied was shown in above Figure 1.

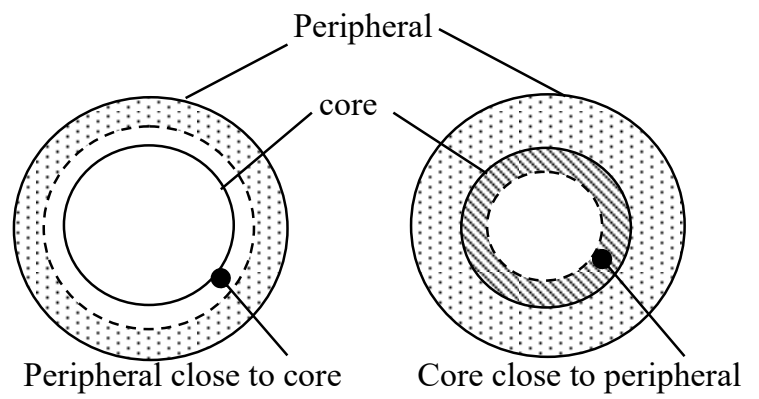

Current

Future

Fig.1 nature of R\&D theme adopting OI 


\section{Hypothesis}

Toray actively promoted OI even after Lehman shock (2008). In 2011, it is surprising, but the keyword OI was stated not only in the R \& D strategy but also in the company's main policy. Nonetheless, facing deterioration of the unprecedented economic environment, it is unlikely that OI tactics will not change at all. OI tactics should also be forced to be modified so that R \& D results can be obtained more efficiently. Under the deteriorating economic environment, efficiency of R \& D investment is indispensable. In other words, I thought that R \& D targets should be shifting. Three hypotheses are presented below.

Hypothesis 1: The technical field of R \& D is shifting. Hypothesis 2: R \& D targets are shifting from peripheral technology to core technology.

Hypothesis 3: R \& D focusing activity is shifting from protect to produce.

\section{Methodologies}

\subsection{Description of method}

Toray started OI since 2002. Also, Lehman shock happened in 2008. Therefore, changes in patent applications were quantitatively analyzed around $1^{\text {st }}$ January 2009.

First analysis subject was technical field. The patent classification indicates the technical field of the patent application. Therefore, it is possible to estimate Toray's technical field by following patent classification. The leading classification of the patent was analyzed. This is because the leading patent classification indicates the subject of the patent application.

Second analysis object was R\&D areas. Chesbrough[1] defined OI as "to create value by organically combining internal and external ideas". Therefore, in the OI application area, the ratio of inventors other than Toray (hereinafter referred to as "external ratio") was inevitably increased. As described above, Toray has strategically defined OI application areas. R \& D of core technology was advanced in black box state. R \& D of peripheral technology of core technology OI applied. Therefore increasing the external ratio meaned that Toray 's R \& D area shifted to peripheral technologies. So it is possible to estimate Toray 's R\&D area by tracking the external ratio. The affiliation of inventors were confirmed from the residences described in patent application. It followed the method of Nishimura et al. [15].

Third analysis object was R\&D focusing activities. Among R\&D investments, activities to produce output lack immediate effect and may be subject to reduction under a bad business environment. Therefore it is possible to estimate Toray's R\&D focusing activities by tracking the direction of output production.

\subsubsection{Technical fields}

Patent applications of Toray filed on 2002 to 2016 were extracted. They were classified into a group whose filing date is 1st Jan. 2002 to 31 st Dec. 2008 and a group whose filing date is 1st Jan. 2009 to 31st Dec. 2016, then each average value of external ratio of the group was calculated. The group whose filing date is 1st Jan. 2002 to 31 st Dec 2016 was hereinafter referred to as "BeforeLS ". The group whose filing date is 1 st Jan. 2009 to 31 st Dec 2016was hereinafter referred to as "After-LS ". Cross tabulation and chi square analysis were performed after calculating the patent classification of each group.

\subsection{2 $R \& D$ area}

After calculating the average value of the external ratio of each group, the average value of each group was tested.

\subsubsection{R\&D focusing activities}

The number of patent applications of Toray filed on 2002 to 2016 were extracted. Among R\&D activities, patent applications were activities targeted for protecting output. As the proportion of patent application activities in $\mathrm{R} \& \mathrm{D}$ activities increased, activities were focused on protecting output rather than producing output. In this study, the ratio of patent applications / R\&D investment amount was calculated and compared before and after Lehman shock.

\subsection{Search system}

Patent applications of Toray group were extracted with 'NRI cyber patent desk 2' (NRI cyber patent desk co., ltd) which was the oldest private patent database in Japan in this study.

\section{Results}

\subsection{Analysis of Technical fields}

13,203 patent applications were applied by Toray between 2000 and 2016. 13189 patent applications that can grasp the inventor's residence were analyzed. The results of cross tabulation and chi-square analysis are shown in Table 1. As is clear from Table 1, a significant difference of $1 \%$ level was observed between the technical field and the number of applications. That is, the technical field and the number of applications are not independent. From the above, it is suggested that Toray is shifting the technical field after 2009 after the Lehman shock. 
Table.1 F-test of external ratio

\begin{tabular}{|c|c|c|}
\hline \multirow{2}{*}{ Technical fields } & \multicolumn{2}{|c|}{ The number of applications } \\
\hline & Before-LS & After-LS \\
\hline A : HUMAN NECESSITIES & 571 & 136 \\
\hline $\begin{array}{l}\text { B : PERFORMING } \\
\text { OPERATIONS; } \\
\text { TRANSPORTING }\end{array}$ & 2082 & 1050 \\
\hline $\begin{array}{l}\text { C : CHEMISTRY; } \\
\text { METALLURGY }\end{array}$ & 2810 & 1418 \\
\hline D : TEXTILES; PAPER & 1818 & 575 \\
\hline $\begin{array}{l}\text { E : FIXED } \\
\text { CONSTRUCTIONS }\end{array}$ & 168 & 27 \\
\hline $\begin{array}{l}\text { F : MECHANICAL } \\
\text { ENGINEERING; } \\
\text { LIGHTING; HEATING; } \\
\text { WEAPONS; BLASTING }\end{array}$ & 112 & 56 \\
\hline G : PHYSICS & 998 & 356 \\
\hline H : ELECTRICITY & 626 & 386 \\
\hline Total & 9185 & 4004 \\
\hline \multicolumn{2}{|c|}{ Chi square value } & 187.23 \\
\hline \multicolumn{2}{|c|}{ Upper probability of chi-square value } & $5.77 \times 10^{-37^{*}}$ \\
\hline
\end{tabular}

\subsection{Analysis of $R \& D$ area}

Test of variance about two-sample of the Before-LS group and After-LS group was implemented. The result of F-test was shown as below Table.2. The result of F-test was conducted. $\mathrm{P}$ value (one-sided) was $8.361 * 10^{-38}$. $2 \mathrm{P}$ value $1.672 * 10^{-37}$ was below 0.25 . Therefore the hypothesis that variance of two samples was equal was rejected. Therefore the t-test that two-sample assuming dispersed was not equal was implemented. The result was shown as below Table.3. P value (one-sided) 0.0018 was $1 \%$ significance level, therefore average external ratio of After-LS group was lower than that of Before -LS group. Therefore concerning Toray patent applications after Lehman Shock, average external ratio was significantly lower.

Table.2 F-test of external ratio

\begin{tabular}{|c|r|r|}
\hline \multirow{2}{*}{} & \multicolumn{2}{|c|}{ external ratio \% } \\
\cline { 2 - 3 } & \multicolumn{1}{|c|}{ Before-LS } & \multicolumn{1}{c|}{ After-LS } \\
\hline Average & 4.020 & 3.249 \\
\hline Variance & 245.397 & 172.667 \\
\hline $\begin{array}{c}\text { The number of } \\
\text { samples }\end{array}$ & 9185 & 4004 \\
\hline $\begin{array}{c}\text { Degrees of } \\
\text { freedom }\end{array}$ & 216 & 217 \\
\hline $\begin{array}{c}\text { Observed } \\
\text { dispersion ratio }\end{array}$ & 1.4212 & \\
\hline $\begin{array}{c}\text { P value } \\
\text { (one-sided) }\end{array}$ & $8.361 * 10-38$ & \\
\hline $\begin{array}{c}\text { F boundary } \\
\text { value one side }\end{array}$ & 1.0453 & \\
\hline
\end{tabular}

Table. 3 t-test of external ratio

\begin{tabular}{|c|r|r|}
\hline \multirow{2}{*}{} & \multicolumn{2}{|c|}{ external ratio \% } \\
\cline { 2 - 3 } & \multicolumn{1}{|c|}{ Before-LS } & \multicolumn{1}{c|}{ After-LS } \\
\hline Average & 4.0201 & 3.249 \\
\hline Variance & 245.397 & 172.667 \\
\hline $\begin{array}{c}\text { The number of } \\
\text { samples }\end{array}$ & 9185 & 4004 \\
\hline $\begin{array}{c}\text { Degrees of } \\
\text { freedom }\end{array}$ & 8995 & \\
\hline t value & 1.6450 & \\
\hline $\begin{array}{c}\text { P value } \\
\text { (one-sided) }\end{array}$ & $0.0018^{*}$ & \\
\hline & $*$ & $1 \%$ significance level
\end{tabular}

\subsection{Analysis of R\&D focusing activities}

The number of patent applications, R \& D investment and the ratio (the number of patent applications/ $R \& D$ investment) was shown as below Table.4 and Figure.2. Toray has halved the number of patent applications since 2009 after the Lehman shock. R\&D investment amount has been increasing since 2002. As the proportion of patent application activities in $\mathrm{R} \& \mathrm{D}$ activities increased, activities were focused on protecting output rather than producing output. The proportion of patent application activities during $\mathrm{R} \& \mathrm{D}$ activities was declining since 2009 after Lehman shock. Therefore after Lehman shock, Toray was concentrating on producing the output.

Table.4 The number of patent applications, R \& D investment and the ratio

\begin{tabular}{|r|r|r|r|}
\hline $\begin{array}{c}\text { Year of } \\
\text { patent } \\
\text { application }\end{array}$ & $\begin{array}{c}\text { The number of } \\
\text { applications } \\
\text { per year } \\
\text { (a) }\end{array}$ & $\begin{array}{c}\text { R \& D } \\
\text { investment } \\
\text { (billion yen) } \\
\text { (b) }\end{array}$ & $\begin{array}{c}\text { Ratio } \\
\text { (a) / (b) }\end{array}$ \\
\hline 2002 & 1504 & 37.6 & 40.0 \\
\hline 2003 & 1313 & 37.4 & 35.1 \\
\hline 2004 & 1126 & 38.4 & 29.3 \\
\hline 2005 & 1253 & 39.7 & 31.6 \\
\hline 2006 & 1285 & 42.3 & 30.4 \\
\hline 2007 & 1283 & 45.8 & 28.0 \\
\hline 2008 & 1421 & 50.0 & 28.4 \\
\hline 2009 & 564 & 46.2 & 12.2 \\
\hline 2010 & 625 & 46.6 & 13.4 \\
\hline 2011 & 638 & 51.5 & 12.4 \\
\hline 2012 & 623 & 53.3 & 11.7 \\
\hline 2013 & 638 & 55.5 & 11.5 \\
\hline 2014 & 518 & 59.5 & 8.7 \\
\hline & & & \\
\hline
\end{tabular}




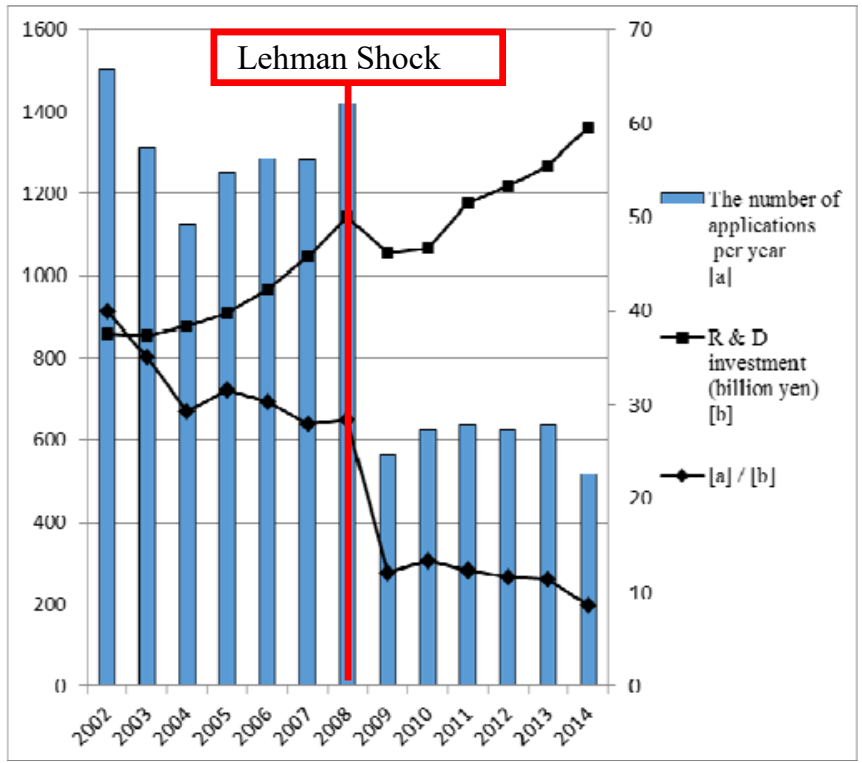

Fig.2 The number of patent applications, R \& D investment and the ratio

\section{Discussion}

Hypothesis 1 was partially supported. It is suggested that Toray is shifting the technical field of R \& D. Hypothesis 2 was supported. Toray has shifted R \& D target research and development area toward core technology. Hypothesis 3 was supported. In Toray, R \& D focusing activities were shifting from protect to produce. Concerning Toray patent applications after Lehman shock, average external ratio was significantly lower. As explained above, Toray's OI is characterized by the selection of open / closed areas. R \& D of core technology was advanced in black box state. R \& D of peripheral technology of core technology was OI applied. R \& D of other technologies was on a case by case. In this case, $\mathrm{R}$ $\& \mathrm{D}$ was advanced in black box state, which was close to core technology. The above result means that Toray has increased the ratio of core technology in the R\&D area since external ratio increases in OI application area. On the other hands, the proportion of patent application activity in R \& D activities had declined since 2009 after the Lehman shock. As explained above, patent applications were activities targeted for protecting output. As the proportion of patent application activities in R \& D activities increased, activities were focused on protecting output rather than producing output. The above result means that Toray focused on producing output rather than output protection in $\mathrm{R} \& \mathrm{D}$ focusing activities.

According to Chesbrow's OI definition [1] and Shimizu et al. [8], OI is the activity aimed at producing output not protecting output and requiring additional costs (e.g. organizational support). Toray has focused on activities to produce $\mathrm{R} \& \mathrm{D}$ output and has revised the tactics of $\mathrm{R}$
\& $\mathrm{D}$ output production. In the $\mathrm{R} \& \mathrm{D}$ output production, the costly OI was reduced and the target of technical field in closed R \& D was shifted.

\section{Conclusions}

In this study, change in OI tactics caused by the deterioration of business environment, Lehman shock, was explained. As a change of OI tactics, quantitative analysis was performed using attribute information of patent applications from three aspects of technical fields, focusing activities and area of $\mathrm{R} \& \mathrm{D}$. The analysis result revealed that the production of core technology output was strengthening in Toray's OI tactics after Lehman shock. The implication of this research is that changes in OI tactics arise due to the great deterioration of the business environment. Changes were observed in the reduction of $\mathrm{OI}$.

There have not been any studies that demonstrate changes in OI tactics caused by deteriorating business environment objectively and quantitatively for one enterprise or group of enterprises. OI presents a kind of boom aspect in Japan. However it was under study how OI tactic changes when an enterprise faced a major deterioration of business environment like Lehman shock. This was because OI was relatively new concept and accumulation of practical work in enterprises was small. It was desirable to enhance empirical research in order for OI to further penetrate Japanese enterprises. This study was considered to be the first step.

This was the first study to analyze changes in OI tactics caused by deteriorating business environment objectively and quantitatively for one enterprise or group of enterprises. This study is thought to be academically meaningful but there are limits as well. The verification of case was limited to the case of Toray of enterprises. Case studies will be conducted in other enterprises as well in future and it is desirable to further verify changes in OI tactics caused by deteriorating business environment.

\section{References}

[1] Chesbrough, H.W., "Open innovation: The new imperative for creating and profiting from technology", Harvard Business Press (2006)

[2] Kazuyuki Motohashi, Yoji Ueda, Motoyasu Mino, "Interview Survey Results and Analysis on New Trends in Open Innovation in Large Japanese Corporations", RIETI Policy Paper Series, 12-P-015 (2012)

[3] Tatsuya Hoshino, "Textbook of open innovation", DIAMOND,Inc, PP.150-151 (2015)

[4] Yuji Ozeki, "Acceleration of R\&D Activities of Toray by Open Innovation", Journal of the Japan Society for Intellectual Production Vol.9, No.1 (2012) 
[5] Takeshi Matsumoto, "Strategic development of open innovation: Open innovation platform structure and practice ", Business Research, No.1055, pp.12-22 (2014) [6] Seiichiro Yonekura, Hiroshi Shimizu, "Open Innovation Management: Challenges for Japanese Firms", Yuhikaku (2015)

[7] I.Sam Saguy, "Paradigm shifts in academia and the food industry required to meet innovation challenges", Trends in Food Science \& Technology 22, 467-475 (2011)

[8] Shimizu,H.,Y.Hoshino,"Collaboration and innovation speed:Evidence from a Prize Data-Set,1955-2010", IIR Working Paper, WP\#15-04(2016)

[9] F. M. Scherer, "Firm Size, Market Structure, Opportunity, and the Output of Patented Inventions", American Economic Review, 55, 1097 (1965)

[10] A. Pakes, M. Schankerman, "The rate of obsolescence of patents, research gestation lags, and the private rate of return to research resources", $R \& D$,

Patents, and Productivity, National Bureau of Economic Research, 73-88(1984)

[11] Z. Griliches, "Patent Statlstics as Economic Indicator : As Survey", Journal of Economic Literature, 21(1), 172 (1990)

[12] M.Trajtenberg, "Penny of Your Quotes : Patent Citations and the Value of Innovations", The RAND Journal of Economics, 21 (1), 172 (1990)

[13] J.O .Lanjouw and M . Schankerman, "The Quality of ldeas ; Measuring Innovation With Multiple Indicators", NBER Working Paper Series, 7345, 1(1999)

[14] Setsuo Yamada, "Empirical Economic Analysis of Patents", TOYO KEIZAI INC,328 (2009)

[15] Junichi Nishimura, Yosuke Okada, "UniversityIndustry-Government Collaboration in Bio-Clusters : Policy evaluation based on patent data", The Journal of Science Policy 24(4), pp.383-399, (2010) 